\title{
Study of the parental assessment of the adaptation of first-graders with health limitations to the educational organization, considering the features of the urban environment
}

\author{
Zhanna Zhuravleva $^{1 *}$, Anna Pavlova ${ }^{1}$, Angelina Mironova ${ }^{1}$, and Viktoryia Hamanovich ${ }^{2}$ \\ ${ }^{1}$ Moscow City University, Department of Speech Therapy, Moscow, Russia \\ ${ }^{2}$ Belarusian State Pedagogical University named after Maxim Tank, Institute of Inclusive Education, \\ Department of Pedagogy and Psychology of Inclusive Education, Minsk, Belarus
}

\begin{abstract}
A dmission of a child to an educational organization is a difficult period for him. What should be considered when creating an educational environment at school and home? What determines successful adaptation of first-graders to new academic activities, which require from child certain knowledge about the world, good visual-motor coordination, possession of mental operations, planning skills and self-regulation of behavior, verbal communication, and the manifestation of volitional efforts to fulfill educational tasks? The successful adaptation of a child largely influences his further socialization. Modernization of education, aimed at ensuring its accessibility, individualization, and differentiation, creating conditions for achieving new contemporary quality of primary level of general education, leads to heterogeneity in the composition of pupils in terms of their psychophysical development. This complicates the adaptation of both firstgraders with health limitations $(\mathrm{HL})$ and children with regular development. Attracting intellectual and socio-cultural resources of the city in education, socialization, and adaptation of children with $\mathrm{HL}$ to new social conditions are becoming an urgent issue. The purpose of the research is to study the parental assessment of adaptation of a first-grader with $\mathrm{HL}$ to the educational organization in the urban environment. The authors of the article compiled a questionnaire for parents to determine the features of adaptation to the school life conditions of their children. The article presents the analysis results of the conducted survey. Research methods include quantitative assessment and qualitative analysis of the survey, as well as content analysis of relevant literature sources. The present research is caused by the insufficient theoretical study and practical development of issues related to the adaptation of first-graders with HL by parents.
\end{abstract}

Keywords: school adaptation, children with heal th limitations, the role of the family, primary level of general education, urban environment.

\footnotetext{
* Corresponding author: juravlevaj@mgpu.ru
} 


\section{Introduction}

The principles of social equality, justice, universal solidarity, and mutual responsibility serve as the basis for the development of contemporary Russian society. The problems of The principles of social equality, justice, universal solidarity, and mutual responsibility serve as the basis for the development of contemporary Russian society. The problems of families raising children with $\mathrm{HL}$, and, in particular, the needs for the quality of education received at each level, are becoming a priority in the development of a particular city and society in general. The legislative framew ork of the Russian Federation declares support for the family of a child with $\mathrm{HL}$, as well as access to education for children regardless of their psychophysical development. The use of social and cultural resources of the city by general education organizations in the educational process creates a basis for adaptation, socialization, and inclusion of children with $\mathrm{HL}$ at all levels of education.

Adaptation to schooling of children with normal and abnormal development is the research subject of both domestic and foreign researchers (M .M. B ezrukikh, I.A. B elicheva, M.R. Bityanova, A.L. Venger, L.A. V enger, T.V. Dorozhevets, Y a.L. Kolomensky, N.G. Korobeinikov, T.V. Kostyak, M.A. Kuvyrtalova, L.S. Luskanova, E.A. Panko, T.A. Solovieva, M.A. Fadina, M. B enz, A. Lillvist, M. Magdalena, M. M argalit, G. Mireles, A. Resch, E. Shilshtein, and J. W ilder). M ost of them adhere to the traditional approach in the interpretation of the concept of adaptation, which comes from the Latin words adaptatio, adaptare, adaptio, adapto, which means to adapt, adjust. In this context, adaptation is considered as "the adjustment of the organism, personality, and their systems to the nature of individual influences or the changed conditions of life in general; and compensates for the insufficiency of habitual behavior in new conditions" [1].

The analysis of literature sources shows the lack of theoretical and practical development of the problem of adaptation of first-graders with $\mathrm{HL}$ to the educational organization of the urban environment, which requires additional research in this area and determines the relevance of the present research.

Features of psychophysical devel opment of pupils with $\mathrm{HL}$, difficulties in interacting with the social urban environment, and reduced ability to respond adequately to changes and adapt to increasingly complex requirements cause difficulties that these children face when moving to a new level of education [2].

A daptation of a child with $\mathrm{HL}$ to an educational organization cannot be achieved without involving their parents, who provide favorable social and everyday conditions, monitor compliance with all regime points, create a friendly attitude, and build interaction among all family members, supporting a child in difficult situations, which creates the basis for optimal socialization of a first-grader with $\mathrm{HL}$ in the urban educational space and their adaptation to school [3-9]. Information from parents about the condition of a first-grader with $\mathrm{HL}$ outside of an educational organization helps to determine the degree of readiness for school, and identify the reasons for their maladaptation [10].

\section{Methods}

To study the parental assessment of adaptation of a first-grader with $\mathrm{HL}$ to the educational organization in the urban environment, the authors have compiled a questionnaire for parents, which consisted of 26 questions related to the peculiarities of the process of adaptation to the school life conditions.

In M arch 2020, 27 parents of first-graders with developmental disabilities, who studied at educational organizations in M oscow and the M oscow Region, took part in the survey. The questionnaires were filled out for 16 girls and 11 boys. 


\section{Results and discussion}

According to the survey results, the majority of parents of children with $\mathrm{HL}$ answered the question about children's desire to go to school in the morning as "mostly yes" - 17 people $(62.9 \%)$; "yes" - five people (18.5\%); and "no" - five people (18.5\%). This means that the majority of respondents' (23 people or $85.1 \%$ ) children were motivated to study and were interested in attending school. Only five respondents' $(18.5 \%)$ children did not want to go to school, although enough time had passed for children to adapt to the new role of the pupil (Fig. 1).

Always willing

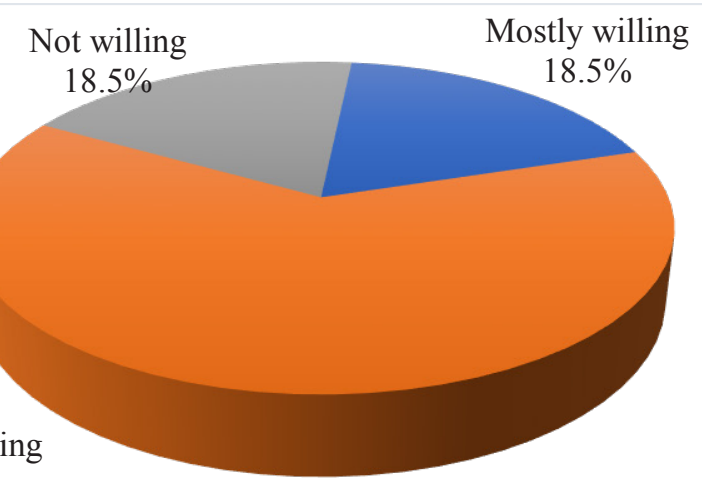

Fig. 1. Answers to the question of whether a child was willing to go to school in the morning.

A ccording to the majority of parents (26 people or $96.2 \%$ ), their children have adapted to the new school regime, only one respondent (3.7\%) noted that their child was experiencing certain difficulties. The daily routine for a first-grader was becoming important due to the increased workload and the emergence of new responsibilities that required children to be more focused, disciplined, and have self-control skills [11].

A the same time, according to the results of the survey, one child (3.7\%) experienced an increase in respiratory diseases. However, this child did not have any difficulties in adapting to the school schedule or unwillingness to attend school in the morning. A slight increase in respiratory diseases was observed in seven children (25.9\%), while in 19 first-graders $(70.3 \%)$ such a trend was not observed.

The following answers were received to the question of whether a child experienced school failures: 13 respondents (48.1\%) answered "yes, they were worried"; 13 respondents $(48.1 \%)$ answered "sometimes, from time to time"; and just one respondent $(3.7 \%)$ gave a negative reply. A ccording to the data obtained, the vast majority of children ( 26 first-graders or $96.2 \%$ ) were worried about learning at school. U sually, all children are faced with school failure. Parents need to teach the child to respond adequately to school situations, especially acute ones, as well as to talk with the child in a confidential environment, and to be as attentive as possible to his emotional state. If necessary, parents should seek help from a teacher and school psychologist $[12,13]$.

The responses to the question of whether a child or a family had any problems associated with starting school, were as follows: 10 families of first-graders with $\mathrm{HL}$ faced several problems (37\%), 15 families (55.5\%) did not face difficulties, and two families (7.4\%) found it difficult to answer. It should be noted that among the children with $\mathrm{HL}$ who faced various problems with the beginning of school, three first-graders (11.1\%) were unwilling to go to 
school in the morning, while two first-graders (7.4\%) previously experienced difficulties in adapting to pre-school education (Fig. 2).

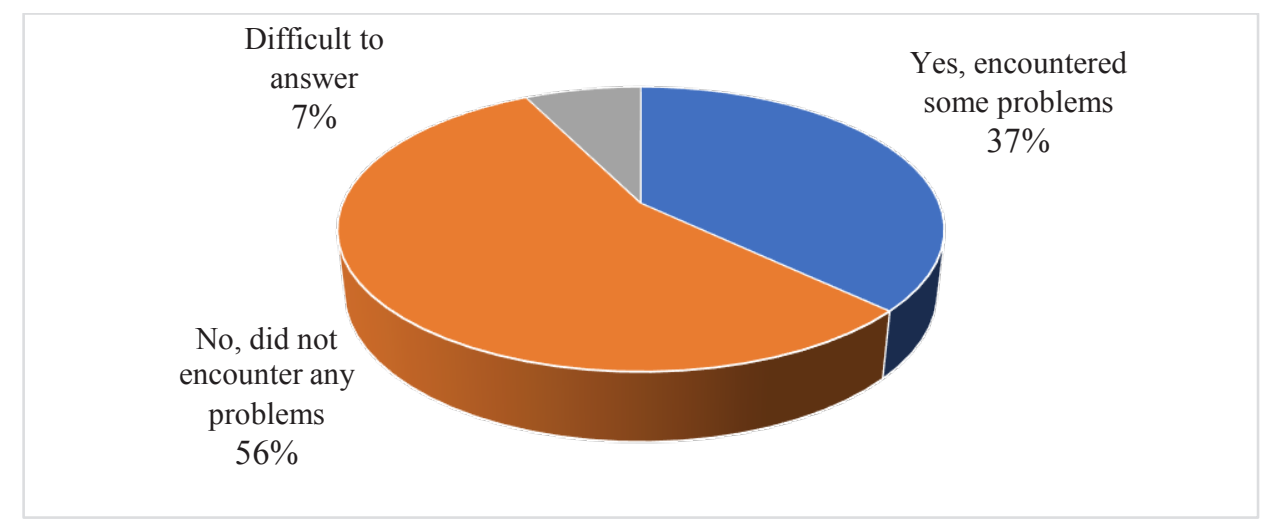

Fig. 2. Answers to the question of whether a child or a family encountered any problems associated with the beginning of schooling.

At that, three people $(11.1 \%)$ were constantly seeking advice from a teacher or psychologist regarding difficulties encountered; 11 people $(40.7 \%)$ have sought advice several times, and 13 people (48.1\%) have never sought advice.

It is worth noting that out of 10 families of first-graders with developmental disabilities, who encountered various kinds of difficulties, seven respondents $(25.9 \%)$ sought advice several times, while three respondents (11.1\%) never sought advice. Out of 15 families that did not face any problems with the beginning of school education, two respondents $(7.4 \%)$ were constantly seeking help; four respondents (14.8\%) applied for advice several times, while nine respondents (33.3\%) have never sought advice.

According to the results of a survey of respondents concerning the sleep disorders in children with HL, the answers were as follows: three parents (11.1\%) often observed sleep disorders in their children; four parents (14.8\%) sometimes noted sleep disorders, and 20 parents $(74 \%)$ never noted sleep disorders.

The majority of respondents (19 people, or $70.3 \%$ ) answered negatively to the question of whether a child complained to parents about unreasonable abdominal pain or nausea; six respondents (22.2\%) noted that their children complained sometimes; while two respondents (7.4\%) answered positively (they complained quite often). At the same time, children who faced certain problems associated with the beginning of school education and who had sleep disorders complained most often. Timely detection of borderline neurological disorders is of particular importance in a contemporary school environment [14].

When respondents were asked whether they noticed obsessive movements and actions in the behavior of their children (biting a pen/nails, sucking a finger/hair, hiccupping, blinking frequently, etc.), the majority of parents (14 respondents, or 51.8\%) answered negatively, sometimes these manifestations in behavior were noted by seven parents (25.9\%), while four $(14.8 \%)$ parents often noticed the above behavior features. One parent $(3.7 \%)$ found it difficult to choose an answer (Fig. 3). 


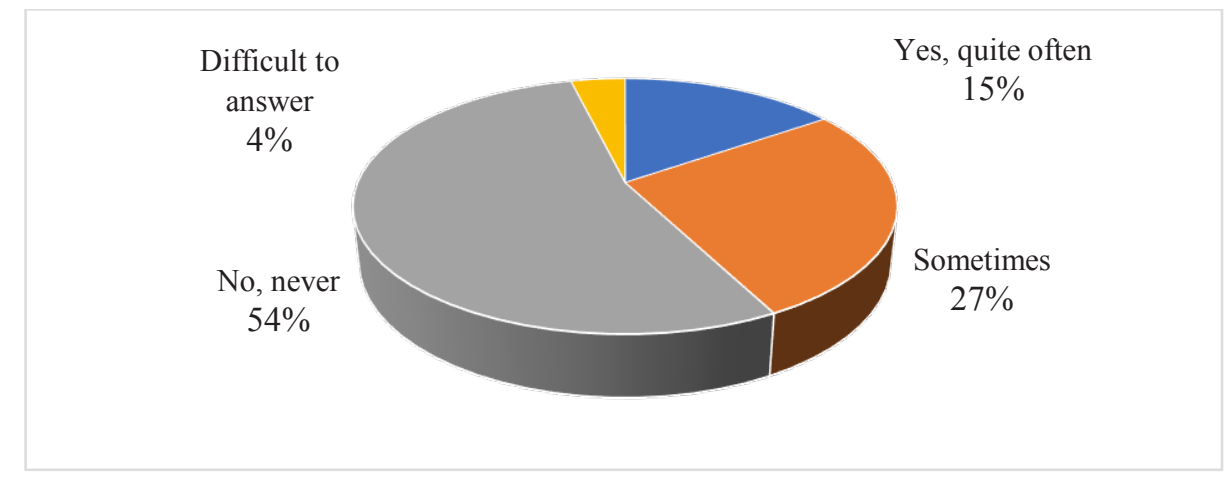

Fig. 3. Answers to the question of whether a child manifested behavior, such as biting the pen/nails, sucking the finger/hair, hiccupping, blinking frequently, etc.

Manifestations of such obsessive actions in a first-grader may be associated with emotional stress, both at school and home, rejection of the current situation, and the inability to adapt to new conditions. If this obsessive behavior occurs, parents should contact a psychologist and physician [15].

For the question of whether a first-grader complained to his parents about fatigue and headache, the following answers were received: "yes, he complains" - 6 people $(22.2 \%)$; "sometimes" - 12 people (44.4\%); and "no" - nine people (33.3\%). According to the observations of medical professionals and psychologists, many first-graders had a decrease in blood pressure (a sign of fatigue), while some had a significant increase in blood pressure (a sign of overwork). The answers to the question are shown in Figure 4.

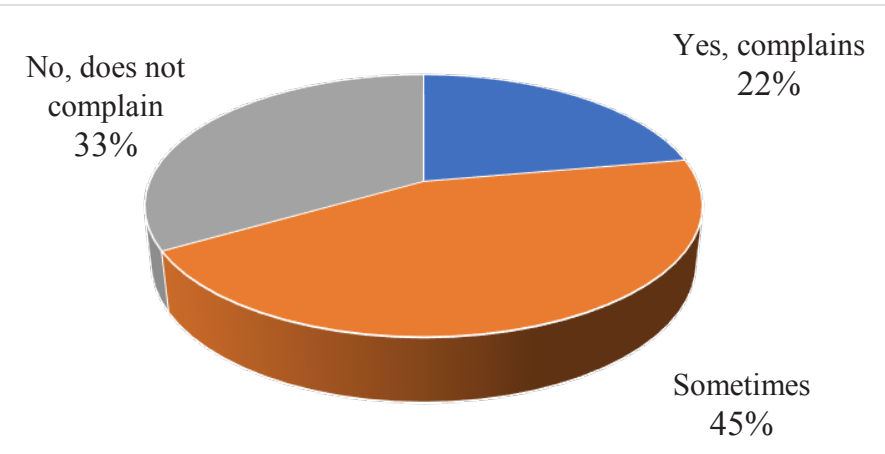

Fig. 4. Answers to the question of whether a first-grader complained to his parents about fatigue and headache.

These symptoms are manifestations of difficulties in getting used to school and overexertion of the body, which affects the child's behavior both at school and home. In the case of emotional fatigue, the child may show "childish" behavior (crying, whims, desire for physical contact), as well as a decrease in the ability to self-regulate behavior.

\section{Conclusion}

I rritability, increased fatigue, unreasonable whims, poor appetite, drowsiness, the need to take a nap after school, night sleep disorders, fear, lack of desire to go to school, etc. are bright signs of maladaptation syndrome of a child with $\mathrm{HL}$ to school learning. These 
manifestations can last about a month or a little more. If these symptoms not only persist but also increasingly manifest themselves, then such a child needs special attention from parents, teachers, a school psychologist, and a physician. Therefore, timely symptoms of school maladaptation will help to find a favorable way out of this situation [16-20].

However, it is not correct to assess the level of children's adaptation to an educational organization only based on just these results. It is necessary to conduct a comprehensive diagnostics of adaptation features in children with $\mathrm{HL}$, which will help to identify ways to optimize their condition. Due to the successful adaptation of children with $\mathrm{HL}$ to the educational organization of the urban environment, their equal starting opportunities are provided at the initial stage of education, which contribute to forming harmonious personality, revealing opportunities for a successful life in contemporary society. Successful inclusion of first-graders with HL in the educational process can be considered as a potential source of social change and possible transformation of society in the present and future.

\section{References}

1. M .A. Fadina, M .A. K uvyrtal ova, Vestnik nauki i obrazovaniya, 13(49), 72-75 (2018)

2. S. Dockett, B. Perry, E. K earney, Exceptional ity education international, 21(2) (2011). https://doi.org/10.5206/eei.v21i2.7675

3. N.K. A ndriyenko, Nachalnaya shkola plyus Do i Posle, 12, 47-51 (2013)

4. Y.A. Y ekzhanova, O.A. Frolikova, To parents of future first graders about school readiness (B ely I.B., M oscow, 2012)

5. Y .A. K ostyunina, M olodoy uchenyy, 2(106), 1020-1024 (2016)

6. A.B. M iroshina, A daptatsiya roditeley $k$ shkole [A daptation of parents to school] (Phenix, Rostov-na-Donu, 2019)

7. V.V.Tkacheva, Y.V. U stinova, N.P. B olotova, Psikhokorrektsionnaya rabota s sem'yami detey s ogranichennymi vozmozhnostyami zdorov'ya [Psychocorrectional work with families of children with disabilities] (INFRA-M, M oscow, 2019)

8. O.V. Y ugova, Cherepovets State U niversity Bulletin, 2(77), 195-203 (2017). https://doi.org/10.23859/1994-0637-2017-2-77-28

9. M. Janus, L. Kopechanski, R. Cameron, D. Hughes, Early Childhood E duc J, 35(5), 479-485 (2008). https://doi.org/10.1007/s10643-007-0217-0

10. J. Wilder, A . Lillvist, Hope, Despair and Everything in Between - Parental Expectations of Educational Transition for Young Children with Intellectual Disability, in Families and Transition to School. International Perspectives on Early Childhood Education and Development, 21, 51-66 (Springer, Cham, 2017). https://doi.org/10.1007/978-3-319-58329-7_4

11. T.V. K ostyak, Psikhologicheskaya adaptatsiya pervoklassnikov [Psychological adaptation of first graders] (A cademia Publishing Center, M oscow, 2008)

12. M.M. A nishchenko, G umanitarnyye nauchnyye issledovaniya, 11(27), 81-83 (2018)

13. Y.A. Y ekzhanova, O.A. Frolikova, Tekhnologii uspekha na starte shkol'nogo obucheniya [Technologies for Success at the Start of School Education] (K rylia, Moscow, 2012)

14. T.S. Zhukova, M .A. K hmelkova, Obrazovaniye. Nauka. Nauchnyye kadry, 6, 175-177 (2013)

15. T.A. Firsova, A.L. Busygina, I.V . A rkhipova, B altic Humanitarian Journal, 7(2(23)), 204-208 (2018) 
16. Y.G. Babich, Bulletin of Scientific Conferences, 10-5(14), 13-14 (2016)

17. I.Y. M eshcheryakova, Sovremennyye nauchnyye issledovaniya i innovatsii, 1(69), 757-761 (2017)

18. M .A. Polshina, Concept: Scientific and M ethodical Electronic Journal, 35, 108-112 (2017)

19. E. Shilshtein, M . M argalit, European J ournal of Special N eeds Education, 34(5), 702711 (2019). https://doi.org/10.1080/08856257.2019.1603600

20. A .J. Resch, G. M ireles, M.R. Benz, C. Grenwelge, R. Peterson, D. Zhang, Rehabilitation Psychology, 55(2), 139-150 (2010). https://doi.org/10.1037/a0019473 